\title{
Educational Reproduction in Great Britain: A Prospective Approach
}

\author{
Richard Breen \& John Ermisch \\ richard.breen@nuffield.ox.ac.uk \& john.ermisch@sociology.ox.ac.uk
}

\author{
Department of Sociology and Nuffield College, Oxford
}

Friday, 26 May 2017

Acknowledgments: We would like to thank the ESR reviewers, Matt Lawrence, participants at the 2016 RC28 Meeting in Bern, Switzerland and at a seminar in the Department of Sociology, University of Trento in December 2016, for comments on earlier drafts. We are grateful for support for this research from the John Fell Oxford University Press (OUP) Research Fund. 
Abstract: We examine the extent to which the educational attainments of a generation are reproduced in Great Britain. We address a very specific question -- what was the effect, among people born around the middle of the $20^{\text {th }}$ century, of having acquired a University degree on the probability of having a child who also acquires a degree? We consider the two central processes involved: the effect of having a degree on whether or not a person had a child and, conditional on having at least one child, the effect of having a degree on whether at least one child acquired a degree. We find a strong and persistent negative effect of having a degree on the chances of having a child but, among those who had a child, the possession of a degree had a large positive effect on the probability of that child also acquiring a degree. These two effects largely cancel out and thus having a degree had a very small effect on the chances of having a child who also had a degree. One major advantage of adopting the prospective approach used here is that it helps to better answer questions concerning the intergenerational effects of changes in education. 


\section{Educational Reproduction in Great Britain: A Prospective Approach}

Education is often seen as an investment, by individuals and governments, that pays off in higher incomes, greater productivity, and perhaps in other respects too, such as healthier and better-informed citizens. But educational investments, especially in women's education, are also thought to increase the education of the next generation. This issue has been of particular interest to social scientists working on developing countries (Heckman and Hotz 1986, Schultz 1993, Mare and Maralani 2007) but studies in developed countries are few and deal only with the US (Behrman and Rosenzweig 2002, Maralani 2013, Lawrence and Breen 2016) and Norway (Ermisch and Pronzato 2011). Here we consider the case of Great Britain.

Behrman and Rosenzweig (2002: 323) point out that "most studies from a variety of countries report a significant positive and robust relationship between women's schooling and the schooling of their children". Yet such a positive relationship is not sufficient to tell us how investments in the education of one generation affect the education of the next. It takes no account of other behavioural consequences of increasing education, particularly the consequences for fertility: these are likely to be important, given the negative association between education and fertility found in many countries. Furthermore, if we are to say anything about the possible consequences of changing women's educational attainment we require more than evidence of associations between, say, education and fertility and between the education of parents and their children: we need to establish the degree to which they are the result of causal relationships. Accordingly, in this paper we model some of the behavioural links between the educational attainment of successive generations of men and women in Britain, and we try to assess the degree to which these links are relationships of cause and effect. Our study thus attempts to give an account of some of the causal pathways that link the educational attainments of successive generations.

\section{Prospective approaches to intergenerational transmission}

The specific question we address is: what is the effect of having acquired a University degree on the probability of having a child who also acquires a degree? We are thus 
adopting what has now come to be called a 'prospective' approach to the study of intergenerational transmission (Song and Mare 2015, Lawrence and Breen 2016), in contrast to the more conventional retrospective one. Whereas the retrospective approach uses "data on a sample or population of adults and [compares] their statuses with those of their parents" (Lawrence and Breen 2016: 1, parentheses added), the prospective approach starts with a birth cohort and follows it forward to understand how it reproduces itself socially.

The retrospective approach has been used in many valuable and informative studies of intergenerational mobility yet, by starting with child-parent pairs, it omits the crucial role of family formation. This leads to two serious limitations in our understanding of intergenerational transmission. First, it neglects the fundamental point that if people are to pass advantages and disadvantages to their children they must have children to whom they can pass them (Maralani 2013). Secondly, it neglects the role of family processes in shaping what is passed to the next generation. The resources that a person accumulates help to determine her chances of marrying or forming a partnership, the kind of person she marries and the resources her partner brings, the age at which she marries, the stability of that relationship, and, of course, the number of children she produces (Mare and Maralani 2007; Mare 2011; Maralani 2013). The conventional view of mobility, based on a retrospective design (people's status is linked to that of their parents), cannot address mechanisms of this kind. By contrast, these mechanisms are easily incorporated into a prospective approach.

A prospective approach also helps to better answer important policy questions. For example, Maralani (2013) finds that, in the US, increasing the proportion of women with a college degree would increase the educational attainment of the next generation of whites, but would have little if any effect on the educational attainment of African Americans in the next generation. This is because African American women with a college degree are less likely to marry and less likely to have children and so their educational advantages are often not passed on to another generation. This result could not have been discovered using the conventional approach to mobility analysis because, by starting with parent - child pairs, it ignores the crucial impact of education on fertility. 
There is relatively little work linking social mobility and demography through a prospective perspective. The approach was set out by Mare in programmatic (2011) and methodological papers (Song and Mare 2015) and has been used in a small number of empirical analyses (Mare and Maralani 2006 who study Indonesia; Maralani 2013 [the US]; Hillmert 2013 [Germany]; Lawrence and Breen 2016 [the US]). ${ }^{1}$ Our paper focuses on the extent to which the educational attainments of one generation are reproduced in Great Britain. A full understanding of this would encompass a range of analyses -- how education determines the resources and rewards that people accumulate, how these are linked to family formation and fertility, and how all these come together to shape the education of the next generation. This would be an ambitious set of analyses, not least in the demands it would make of data. Here we adopt a more limited approach. On the one hand, we start with a very specific question -- what is the effect of having acquired a University degree on the probability of having a child who also acquires a degree? - that limits the scope of our analysis to one particular kind of educational attainment. On the other hand, we restrict ourselves to the consideration of what we believe to be the two central processes involved: the effect of having a degree on whether or not a person has a child and, conditional on having at least one child, the effect of having a degree on whether at least one child acquires a degree. In a more descriptive way we also analyse the role of educational assortative mating, in both its influence on parenthood and the chances of a child obtaining a degree, but we do not study differential fertility. Bringing these aspects into a causal estimation framework is important, but beyond the scope of what we seek to achieve here.

The first process we study is the effect of a degree on whether someone has children. Although the evidence on the association of education and fertility stretches back decades, there have been few studies of the causal effect of education on fertility and even fewer that examine completed fertility. These arrive at conflicting conclusions. ${ }^{2}$ In

\footnotetext{
${ }^{1}$ One can find the precursors of this approach in a number of papers linking mobility and demography but which, with the exception of Duncan (1966), seem never to have entered the mainstream of mobility research. These include, among others, Matras (1961), Hodge (1966), Preston (1974), and Preston and Campbell (1993).

${ }^{2}$ Fort, Schneeweis and Winter-Ebmer(2016) estimate the causal effect of an additional year of education on completed fertility at low education levels, exploiting compulsory schooling reforms in a number of European countries. A significant negative effect is found in England (using the increase in the schooling
} 
our case, we assume no unmeasured confounders and use inverse probability of treatment weighting, iptw, to obtain causal estimates. We then test the sensitivity of our estimates to the assumption of no unmeasured confounders, using a method proposed by VanderWeele and Arah (2011).

The second process is the effect of a degree on the acquiring of a degree by one's child. Of necessity this equation is estimated conditional on having at least one child. The same iptw approach is used in our equations for whether the parent has at least one child who acquired a degree or not. ${ }^{3}$ Here there is also an issue of sample selection, because we can only utilize cases for our final outcome in which a person had at least one child who was old enough to have potentially acquired a University degree and whose highest level of education is known to us.

In the next section of the paper we describe the data we use. We present some descriptive statistics showing long term trends in educational attainment in Great Britain and we also show the relationships between education, marriage, fertility, and children's education in our data. To go beyond description to causal estimates we use inverse probability of treatment weighting to address selection into degree status and non-random observation of child's degree status, and this is described in the subsequent section of the paper. Our results follow. We then examine the role that processes of educational assortative mating play in shaping our estimates. The final part of the paper summarises our findings and presents our conclusions. Further details of our analyses are provided in a set of online appendixes.

\section{Data}

The data used in most of our analyses come from the British Household Panel Survey (BHPS) and we focus on people born between 1936 and 1961 and their children (if they have any). Education for respondents and children is measured as their highest level of

age from 14 to 15 in 1947 as an instrument), but not in the other countries studied. Fort et al. (2016) review other studies using compulsory schooling reforms and find mixed results. Clark and Del Bono (2016) find a strong negative effect of attending a selective grammar school on the probability of Scottish women ever having a child ( -0.08 percentage points).

${ }^{3}$ We also consider the robustness of our results, depending on whether we focus on the oldest child or a random one. 
education observed over the 18 waves (1991-2008) of the BHPS. ${ }^{4}$ We consider only children aged 23 or older at the time our most recent data were gathered because we need them to be old enough to have potentially acquired a University degree.

We chose respondents born between 1936 and 1961 because we needed them to be neither too old nor too young. Since we collect data on their children only if they were co-resident at some time in the panel study, 'too old' could mean their child was observed living with them when he/she was quite old (e.g. a person born in 1935 would be 56 in 1991 (the first year of the BHPS) making their child about 31 in 1991). For this reason we included only those born since 1935. Equally, we require our respondents not to be 'too young' because, in that case, their children might not be old enough to have obtained a degree (e.g. a person born in 1962 would be 46 in 2008 (the last year of the BHPS) making their children 21 or under in 2008, too young to have obtained a degree). This led us to include those born before 1962 (but we also condition on the child being 23 or older at the last time he/she is observed in the data). Online appendix A describes in more detail how our BHPS dataset was constructed.

We draw on Understanding Society for descriptive statistics and model estimates for different birth cohorts. Understanding Society (a successor to the BHPS, which included BHPS respondents from its second wave onwards) is a nationally representative household survey from the United Kingdom. It interviewed nearly 51,000 people in its first wave, and five waves are now available for analysis. Each person aged 16 or older answers the individual adult interview questionnaire. Information about children's highest qualification was elicited by a series of questions in the main interviews. Questions about each parent's educational qualifications were asked in the first (20092010) and second waves (2010-2011) of the study. Subsequent waves were used to obtain parents' educational information not collected in the first wave and to obtain updates of the respondents' own educational qualifications. In the first wave a childbearing and partnership history was collected for each person.

\footnotetext{
${ }^{4}$ We also follow surviving BHPS respondents into waves two through five of Understanding Society (see below) to update their educational qualifications. BHPS respondents joined Understanding Society in its second wave if they had not dropped out of the panel before that.
} 


\section{Descriptive Statistics}

Figure 1, using data from Understanding Society, reveals the secular increase in the acquisition of a degree among children born in the later part of the $20^{\text {th }}$ century. The figure shows, for children born to men and women in one of 14, three-year birth cohorts from 1943-45 to 1982-84, the percentage who obtained a degree according to whether or not their parent had a degree. The figure shows the growth in the percentage of children with a degree, particularly among children of women without a degree. Given that the great majority of parents in these birth cohorts did not have a degree, the overall growth in University graduation in the middle and later part of the $20^{\text {th }}$ century was heavily driven by the trend shown by the 'No degree' lines.

Figure 1 here

Table 1 shows the distribution, over the four central variables used in our analyses, of men and women in the BHPS data who were born between 1936 and 1961. In contrast to retrospective studies, information about parent's education is reported by the parent themselves. On the left of the table we see that only $14 \%$ of men and $10 \%$ of women born in this period attained a University degree. The central part of the table shows a number of differences between men and women in marriage and fertility and in the extent to which the possession of a degree was associated with differences in marriage and fertility. For both sexes, those with a degree were less likely to marry, but the gap was greater among women (a 7.5 percentage point gap compared with 3.6 among men). This arose entirely because women without a degree were much more likely to marry than were men without a degree. Lawrence and Breen (2016) report the same finding among men and women born at around the same time in the US. In both cases the explanation probably lies in the higher incidence of hypergamy than hypogamy in many mid-20th century societies. As Table 1 shows, there was no difference in marriage rates between men and women with a degree.

Table 1 here 
Women in Britain were more likely than men to have children, ${ }^{5}$ and rates of childlessness were higher for men and women with a degree. But the difference between those with and without a degree was, once again, larger among women (an 8.1 percentage point gap compared with 2.4 percentage points among men). Finally, focusing on men and women who had children for whom we have information on at least one child's education beyond age 22 , we see that, among those who did not have a degree, the probability of having a child who acquired a degree was much the same for men and women, but having a degree conferred more advantage on their children among men than women.

In summary, women with a degree, when compared with those without, had lower chances of marriage, a higher risk of being childless, and gained a smaller educational advantage for their children than did men with a degree. These factors combine, so that women and men with a University degree had, on average, a probability of having a child who also had a degree that is 0.15 (s.e. $=0.03$ ) higher than the probability for those who did not have a degree. ${ }^{6}$

\section{Propensity scores and iptw}

If we want to describe the extent to which people with a degree reproduce their status we do not need causal estimates. But if we are to answer questions about the effect of acquiring a degree on how likely people are to have a child with a degree we need to know how far educational status has an effect on, rather than simply an association with, the educational status of the next generation. And because we want to know the average effect for all persons born between 1936 and 1961 we estimate the average treatment effect, ATE, of a degree on having a child with a degree. For selection into degree status, we follow Lawrence and Breen (2016) in dealing with selection on

\footnotetext{
${ }^{5}$ The larger percentage childless among men could be due in part to their under-reporting their fertility (see Rendall et al. 1999).

${ }^{6}$ These estimates come from a sample of childless and parents for whom we know their child's education at age 23 or older. Alternatively, we can use the figures in Table 1 and compute the probability of having a child who obtains a degree by taking the probability of having a child (from the 'Child' column in Table 1) and multiplying it by the probability of having a child who obtains a degree conditional on having at least one child (from the 'Child with Degree; column of Table 1). This yields an estimate of the impact of having a degree of 0.19 for women and 0.26 for men. The difference reflects the selection of children aged 23 or older among those with children: we are more likely to observe a child aged 23 or older among people who have a degree.
} 
observables through inverse probability of treatment weighting, using weights computed from the propensity score. We follow a similar approach with respect to the sample selection process for observing a child's degree status. All our variables are binary and our estimates come from linear probability models.

We illustrate our approach in the case of the effect of a woman's education on the probability she has a child, $E\left[C_{i}\right]$, where $C_{i}=1$ if she has a child and $C_{i}=0$ if she does not. Let $D_{i}=1$ indicate that the mother has a degree and $D_{i}=0$ if she does not. We are interested in the average treatment effect (ATE): $E\left[C_{i 1}-C_{i 0}\right]$, where $C_{i 1}$ is the potential outcome under $D_{i}=1$ and $C_{i 0}$ is the potential outcome under $D_{i}=0$ for the $i$-th person. Clearly, only $C_{i 1}$ or $C_{i 0}$ is observed for any one person. The observed outcome is $C_{i}=C_{i 0}+$ $\left(C_{i 1}-C_{i 0}\right) D_{i}$

The observed difference in the probability of having a child between those with and without a degree is

$$
\begin{aligned}
& E\left(C_{i} \mid D_{i}=1\right) \quad E\left(C_{i} \mid D_{i}=0\right)= \\
& E\left(C_{i 1} \quad C_{i 0}\right)+ \\
& \left\{E\left(C_{i 0} \mid D_{i}=1\right) \quad E\left(C_{i 0} \mid D_{i}=0\right)\right\}+ \\
& \left(1 \quad E\left(D_{i}\right)\right)\left[E\left(C_{i 1} \quad C_{i 0} \mid D_{i}=1\right) \quad E\left(C_{i 1} \quad C_{i 0} \mid D_{i}=0\right)\right]
\end{aligned}
$$

The first term on the right hand size of equation [1] is the ATE. The second term, in the curly brackets, is the 'selection effect': the difference in the baseline probability in potential outcomes between those who have a degree and those who do not. The third term, in square brackets, is the difference between the 'treatment effect on the treated' (i.e. those obtaining a degree, ATT) and the 'treatment effect on the untreated' (ATU), weighted by the probability of not being treated. If the treatment effect is constant, as is the case in linear models (which we use), $A T T=A T U$ and the last term disappears.

The propensity score is the probability that $D_{i}=1$ conditional on the variables $X_{i}$ : $E\left(D_{i} \mid X_{i}\right)=p\left(X_{i}\right)$. We assume that $C_{i 1}$ and $C_{i 0}$ are independent of $D_{i}$ given $p\left(X_{i}\right)$ :

$$
E\left(C_{i 1} \mid p\left(X_{i}\right), D_{i}=1\right)=E\left(C_{i 1} \mid p\left(X_{i}\right), D_{i}=0\right)
$$


and

$E\left(C_{i 0} \mid p\left(X_{i}\right), D_{i}=0\right)=E\left(C_{i 0} \mid p\left(X_{i}\right), D_{i}=1\right)$

The weighting approach to propensity score estimation takes advantage of the fact that, if this conditional independence assumption holds, $E\left(C_{i 1}\right)=E\left(C_{i} D_{i} / p\left(X_{i}\right)\right)$ and $E\left(C_{i 0}\right)=E\left(C_{i}\left(1 \quad D_{i}\right) /\left(1 \quad p\left(X_{i}\right)\right)\right)$. Thus, the average treatment effect (ATE) is the sample analogue of $E\left(C_{i} D_{i} / p\left(X_{i}\right)\right)-E\left(C_{i}\left(1-D_{i}\right) /\left(1-p\left(X_{i}\right)\right)\right)$, which is

$$
\frac{1}{N} \quad{ }_{1}^{N}\left\{\left[C_{i} D_{i} / p\left(X_{i}\right)\right] \quad\left[\left(1 \quad D_{i}\right) C_{i} /\left(1 \quad p\left(X_{i}\right)\right)\right]\right\}
$$

where $\mathrm{N}$ is the total sample size. In the weighting approach, people with a low (high) probability of treatment receive a higher (lower) weight in the estimation. Further details of how we implemented this approach are given in on-line appendix B. Cerulli (2014) provides iptw formulae for the ATE and other treatment effects. Hernan and Robins (2006) is a straightforward introduction to the iptw method.

Our estimate of the propensity of having a University degree uses as predictors the focal person's father's social class, mother's and father's education, and whether or not the mother had a job when the person was 14 . These appear to be some of the most relevant predictors of treatment (i.e. the person's degree status) and in finite samples a relatively small set may have efficiency gains. The estimates of the propensity score for women are shown in online appendix table $\mathrm{C} 1$ under the assumption that $p\left(X_{i}\right)$ is given by a logit model. The distribution of the estimated propensity score is shown in Figure $\mathrm{C} 1$ in the on-line appendix. The median probability of treatment is 0.067 , the interquartile range is from 0.038 to 0.131 and the maximum in the sample is 0.744 .

The necessity of selection of observations for which we have information on the child's educational attainment beyond age 22 may lead to selection bias. As our other dependent variable is whether the parent has at least one child with a degree, non- 
random selection can arise for a number of reasons. The more children a parent has, the more likely we will find one aged 23 or more who has a degree, all else equal; but having more children could reduce all of their children's chances of obtaining a degree. Also, the children who remain in the panel until age 23 may be different from a randomly chosen child. On average, among parents for whom we track at least one child's education aged 23 or older, we observe 1.5 children per parent, and we are more likely to observe a child among parents who have a degree.

We treat this potential selection issue similarly to selection into parent's degree status. There are two structural equations in which this type of selection arises. In the first, which corresponds to the middle column of Tables 2 and 3 below, we are concerned with the joint outcome of producing a child who obtains a degree, in which the 'zero outcome' includes the childless along with those who have a child who does not acquire a degree. In this case a person appears in our sample $\left(S_{i 1}=1\right)$ if they either have a child who is aged 23 or more and whose educational attainment is known or they are childless, and $S_{i 1}=0$ denotes persons who have a child but we do not observe the child's maximum educational attainment at age 23 or older. In the second, corresponding to the last column of Tables 2 and 3 below, we estimate the impact of a degree on the child's chances of obtaining a degree among only those with a child. Thus, in this case $S_{\mathrm{i} 2}=1$ indicates that there is a child who is aged 23 or more and whose educational attainment is known, and $S_{\mathrm{i} 2}=0$ if there are no children or if there is a child aged less than 23 or whose educational attainment is not known. In the first case, we estimate a propensity score for selection into sample of either childless people or parents for whom we observe the education of a child aged 23 or older. We use this to form another weight and we weight our analysis by the product of this weight and the weight for selection into having a degree or not. The second case is the same except that we derive the second weight from a propensity score for selection into the sample of parents for whom we observe the education of a child aged 23 or older. We use the same set of predictors, denoted $X$, as for selection into having a degree, but we augment it with additional information about whether the information comes from the new, expanded samples for Wales, Scotland and Northern Ireland in comparison with the original BHPS sample, which are strong predictors of observing a child aged 23 or older. We label these variables $Z$. On-line appendix table C2 reports the propensity 
score coefficients for the selection model for $\mathrm{S}_{\mathrm{i} 1}$.

Results

In Tables 2 (women) and 3 (men) we report results from models investigating the effects of having a University degree on having a child who also has a degree using inverse probability of treatment weighting (iptw) described above to adjust for measured confounding. In these analyses we control for a set of three-year birth cohorts and whether someone was foreign-born.

Tables 2 \& 3 here

We find, as expected, that having a University degree had a very strong negative effect on women's fertility $(-0.100$, s.e. $=0.030)$ but no significant effect for men $(-0.040$, s.e. $=$ 0.027): these results are reported in column 1 of Tables 2 and 3. Column 3 of Tables 2 and 3 shows that, among parents, having a degree substantially increased their probability of having a child who obtains a degree: it increased the probability of a child obtaining a degree by 0.275 (s.e. $=0.101$ ) for women and 0.385, (s.e. $=0.067$ ) for men). The estimates in column 3 of the tables should be similar to those that would be obtained from conventional, retrospective studies of the effects of parents' education on the education of their children. They will not be identical because retrospective studies sample on children, not parents, but they will be similar because these estimates, like retrospective ones, condition on a child having been born.

Column 2 of Tables 2 and 3 reports our estimates of the total causal effect of having a degree on having a child who also has a degree (0.097 (s.e. $=0.035$ ) for men and 0.069 (s.e. $=0.046$ ) for women). The difference between this and the direct effect of having a degree on having a child with a degree (0.38 for men and 0.28 for women) is the difference between estimates derived from the conventional approach of intergenerational mobility analysis that conditions on the presence of children, and our approach, which takes into account the consequences of educational attainment for fertility. Had we taken the former set of estimates as informative about the consequences of increasing educational attainment in one generation for the 
educational attainment of their children we would have overestimated the effect by a factor of four, because we would have failed to allow for the negative effects of obtaining a degree on fertility.

Earlier we reported that men women with a University degree had, on average, a probability of having a child who also had a degree that is 0.15 (s.e. $=0.03$ ) higher than the probability for women who did not have a degree. In the comparable estimates in column 2 of Tables 2 and 3, these numbers decline to about one-half of the descriptive difference we found for women and two-thirds of that for men. The reduction from using the iptw estimates (and relative to the OLS estimates in Tables 2 and 3) reflects the differential probability of selection into parent's degree status associated with the parent's family background.

Another approach to using our limited information on offspring's education is to choose to analyse the attainment of just one of the children aged 23 or older for whom we know their education. Focusing on women, if we choose the oldest child in our data, then the unconditional estimate of mother's degree status on the child obtaining a degree is 0.08 (s.e.=0.05). If we choose a child at random, than this unconditional effect is 0.09 (s.e.=0.05). Thus, the results are similar, but less precisely estimated. The corresponding conditional estimates are a little larger than those in Table 2, 0.34 (s.e.=0.09) and 0.32 (s.e.=0.11), respectively, but not significantly so.

\section{Sensitivity Analyses}

We test the sensitivity of our results to unmeasured confounding using a general technique advanced by VanderWeele and Arah (2011). We outline it in detail in on-line appendix D, though the principle is straightforward. An unmeasured confounder will bias causal estimates if it is associated both with the treatment indicator (in our case, having a University degree or not) and the outcome (having a child in one case, having a child with a degree in the other). The test varies the strength of these relationships and investigates how large they would have to be in combination to reduce the estimated causal effect to zero or to statistical non-significance. In our implementation of the approach we have expressed the strength of the relationship between unmeasured confounders and treatment (called ) in relation to the strength of the relationship 
between our propensity score and treatment, and the relationship between unmeasured confounders and the outcome of having a child or having a child with a degree (called ) in relation to the strength of the relationship between our propensity score and these outcomes. In other words, we can express the extent of hypothesised unmeasured confounding in our sensitivity analyses in relation to the extent of the measured confounding that we have been able to take into account.

We applied these tests to women only and the full results are reported in on-line appendix D. They show that our causal estimates using IPTW for the effect of having a degree on having any children are very robust. Our estimate of this effect is -.100 (.03) for women. To reduce this to non-significance (at the $\mathrm{p}<.05$ level) requires that both and are at least twice as large (in absolute terms) as we observe for the propensity score. Our estimate of the effect of a woman having a degree on a child's having a degree (among parents only) was .275 (.102). To reduce this to non-significance requires that both and to be as large as we observe for the propensity score. On this basis we are confident that unobserved biases are not driving our findings of significant causal effects of having a degree on having children. If the unmeasured selection were as large as measured selection, our estimate of the effect on having a child with a degree among parents would be reduced to statistical non-significance. But to reduce the effect of a degree on having a child to non-significance would require unobserved selection to be at least twice as large as observed.

\section{Trends over birth cohorts}

The negative effect of a degree on fertility is not a peculiarity of women born between 1936 and 1961. Figures 2 and 3, based on data from Understanding Society, use overlapping five-year cohorts, born between 1942-46 and 1972-76. Figure 2 shows the percentage of women and men who had a child, distinguishing by whether they had a degree or not. Members of both sexes who had a degree were less likely to have children, but the difference between those with and without a degree is much larger among women. Figure 3 uses iptw to take account of measured confounders of the relationship between having a degree and having a child. The confidence interval around the estimates for men always overlaps zero but for women born after 1944 
there is a statistically significant negative effect (averaging around 10 percentage points) of having a degree on the probability of having a child.

Figures 2 and 3 here

\section{Going behind the causal effect: partnerships and assortative mating}

We have found a substantial difference between conditional and unconditional estimates of the effect of a degree, and this difference is driven by the effect of a degree on the probability of becoming a parent. In this section we take a more descriptive approach to help understand the role played by marital and cohabiting partnership in generating our estimates of the causal effect of a degree on having a child who acquires a degree.

We obtain information about a person's partner by matching them to the last partner we observe them living with in the BHPS. This may not be the partner who is the parent of their children, but we assume that, in such cases, they had their children with a partner (or partners) who was similar in terms of degree status. As Figure 4 shows, we compute a series of conditional probabilities that can be linked to obtain an estimate of the impact of a woman having a degree on having a child with a degree, combining the processes of partnering, childbearing and the child obtaining a degree (see online appendix E for details). For estimation of the probability of ever being partnered and the probability of having a partner with a degree, conditional on own degree status, we use inverse propensity score weighting to address non-random selection into degree status. All other conditional probability estimates come from ordinary linear regressions. As earlier, the analysis is confined to women born in the UK between 1936 and 1961, and the model also contains dummies for 3-year birth cohorts in that interval and a dummy for being foreign born. The predicted probabilities average over people in the sample with a given degree status.

Figures $4 \& 5$ here

The impacts of a woman having a degree at each 'stage' of the analysis are obtained by comparing the upper and lower sets of box diagrams in Figures 4 and 5. For example, 
among women with a degree, $85 \%$ had a partner sometime, and among women whom we can match with a partner, $48 \%$ had a partner with a degree and $52 \%$ had a partner without a degree. For both types of partnership, about $80 \%$ had a child, but $74 \%$ of those female parents whose partner also had a degree produced at least one child with a degree compared with $61 \%$ of those whose partner did not have a degree. The comparison with a woman who did not have degree indicates that obtaining a degree increases a woman's probability of having a child with a degree by 0.16 . In contrast, if we assume that everyone had a partner and had a child (i.e. ignoring the partnership and childbearing processes, as is done with retrospective data), then the estimate of the impact of the woman having a degree would be 0.30 .

Given a woman's own degree status, who she partners with matters for transmission of degree status. For non-degree women, their low probability of partnering with a man with a degree damages their chances that their children obtain a degree. If, for example, matching were random so that both degree and non-degree women had the same chances as degree women to match with a man with a degree (equal to the proportion of men with a degree), then the average impact of the woman having a degree on having a child with a degree would fall from 0.16 to 0.12 .

Another counter-factual simulation assumes the same probability of partnering for degree and non-degree women, random matching, and the same probability of having a child for degree and non-degree women (i.e. all three demographic processes are undifferentiated by degree status). In this case the overall effect of a woman having a degree on her child obtaining a degree is 0.20 , indicating that the differentiated demographic processes reduce the impact of having a degree by 0.04 .

Figure 5 shows the same statistics for men. Having a degree increases the probability of having a child with a degree by 0.23 , compared to 0.36 if the partnering and childbearing processes are ignored. If matching were random, then the impact would only fall to 0.22 . Thus, assortative mating is less important in the transmission of degree status for men than it is for women. When we undertake the undifferentiated demographic process counterfactual exercise for men, there is virtually no change in the overall impact of the man having a degree on his child having a degree. Thus, in net 
terms the differentiation of demographic processes does not contribute to intergenerational transmission for men. ${ }^{7}$

This gender difference is evident in Table 4, which summarizes some of the information in Figures 4 and 5. As far as having one or more children is concerned, the important factor is whether or not the woman has a degree. If she has, the probability of having a child is reduced as can be seen by comparing rows 1 and 2 and 3 and 4 of the columns labelled (1) and (2) in Table 4. By contrast, if we compare rows 1 and 3 and 2 and 4 we see that there is no effect of the man having a degree, regardless of whether the respondent is male or female.

For both men and women, differences between degree parents and non-degree parents in the probabilities of a child obtaining a degree are very important. The final two columns of Table 4 show that having two parents with a degree is most beneficial for a child to have a degree, followed by having only the father with a degree, then having only the mother with a degree. But couples in which neither partner has a degree have a much lower probability of any of their children acquiring a degree. We can illustrate the importance of this via a counterfactual, using columns (3) and (4) of Table 4. If a mother without a degree, partnered with a man who also did not have a degree, had the same probability of having a child with a degree as a mother with a degree partnered with a non-degree man (that is, .607 rather than .338) the overall effect, among women, of having a degree on having a child with a degree would decline from 0.16 to -0.04 . Applying the same calculation to men, the effect would decline from 0.23 to zero.

Table 4 here

\section{Conclusion}

The way in which the distribution of education in the parents' generation is transformed into the distribution in their children's generation depends on processes

\footnotetext{
${ }^{7}$ As another check on our results, we used the first five waves of Understanding Society data to model partnership, assortative mating, and childbearing if partnered and combine it with the probabilities of the child obtaining a degree among parents (the last stage of the process) from the BHPS data. In this case, the overall effects of having a degree are similar to what we found from the BHPS data on the demographic processes: 0.18 for women and 0.27 for men.
} 
such as marriage/partnership and fertility as well as the direct links between parents and their child's education. We find that, among parents in the UK born between 1936 and 1961, having a University degree had a strong effect on the likelihood of a child also obtaining a degree: however, having a University degree made people less likely to be parents in the first place. This was particularly pronounced among women (see Brand and Davis 2011 for comparable US findings). As we showed in Figures 2 and 3, this is not an artefact of the particular set of birth cohorts that we analysed. It holds true for birth cohorts of women (though not of men) born between the early 1940s and the mid1970s. As a result, the effect of a having a degree on the probability of having a child who obtained a degree was quite modest: 9.7 percentage points for men, 6.9 for women (though this is not significant at $\mathrm{p}<.05$ ). Further analysis suggests that, for women without a degree, the low probability of partnering with a spouse with a degree plays an important role in producing this effect (but this is not the case for men).

Our causal estimates of the impact of a degree on having a child among those born 1936-61 are robust to different sub-samples (e.g. dropping cases with missing observations on the focal person's parents' education), excluding some variables from the set predicting 'selection' (e.g. focal person's parents' social class), and between the BHPS and Understanding Society data. The estimates of the impact of a degree on a child obtaining a degree among parents are always close to the OLS estimates, as a comparison of the upper and lower parts of Tables 2 and 3 reveal. In conjunction with Figure 1, which shows that large differences in the chances that a child obtains a degree by parent's degree status are maintained across birth cohorts, the similarity suggests robustness of this effect as well. ${ }^{8}$ Our sensitivity analyses suggest that the effects of unmeasured confounding would have to be several times greater than the confounding we have been able to take into account if they were to reduce to non-significance our estimate of the effect of a degree on having any children. Lastly, the plausibility of such a causal effect is supported by several proposed mechanisms (Ní Bhrolcháin and Beaujouan 2012 and Fort et al. 2016), though we cannot test them in this paper. For example, it has been argued that acquiring a degree reduces fertility by increasing the

\footnotetext{
8 Furthermore, although the rates at which children acquired a degree increased for parents born between 1936, and 1961, Figures 2 and 3 suggest that, at least as far as the degree - fertility relationship is concerned (and this is the main source of our finding of a modest causal effect), this remained very similar over a much longer period.
} 
opportunity costs of children for women, and/or that the acquisition of a degree changes values and life goals.

These results have consequences for our understanding of how inequalities evolve over generations. Considering only the "robust relationship between women's schooling and the schooling of their children" would lead us to overestimate the effect of schooling in one generation on the schooling of the next. As columns 2 and 3 of Tables 2 and 3 show, the effect of having a degree on a child's probability of obtaining a degree is four times larger among parents than is our estimate of the unconditional effect. Thus a large retrospective effect, much as we see here for the conditional effect, can exist even though people who have a degree do not have a particularly large advantage in their chances of passing that status to children.

The transmission of degree status from a birth cohort is less strong than it is from parents to children because of the lower fertility of people with a degree, especially women. However, their educational status may still be transmitted to a subsequent generation. As Lawrence and Breen (2016: 554) note, graduates who have no children of their own may be beneficial for nephews and nieces or other collateral kin, and they cite Jaeger's (2012: 915) finding that, in the Wisconsin Longitudinal Study data, aunt's education has a significant positive effect on a child's education. This and similar avenues of intergenerational transmission would surely repay further investigation by sociologists of stratification. 
References

Behrman, Jere R. and Mark. R. Rosenzweig. 2002. Does Increasing Women's Schooling Raise the Schooling of the Next Generation? American Economic Review. 92: 323-34.

Brand, Jennie E. and Dwight Davis. 2011. The Impact of College Education on Fertility: Evidence for Heterogeneous Effects. Demography 48: 863-87.

Clark, Damon and Emilia Del Bono. 2016 Long-Run Effects of Attending an Elite School: Evidence from the United Kingdom. American Economic Journal: Applied Economics 8: $150-176$.

Cerulli, Giovanni. 2014. treatrew: A user-written command for estimating average treatment effects by reweighting the propensity score. The Stata Journal. 14: 541-61.

Duncan, Otis Dudley. 1966. "Methodological Issues in the Analysis of Social Mobility." Pp. 51-97 in N.J. Smelser and S.M. Lipset (eds.), Social Structure and Mobility in Economic Development. Chicago: Aldine.

Ermisch, J. and Pronzato, C. 2011.“Causal effects of parents' education on children's education." In: Persistence, Privilege, and Parenting (Tim Smeeding, Robert Erikson and Markus Jäntti, , editors). New York: Russell Sage Foundation.

Fort, Margherita, Nicole Schneeweis and Rudolf Winter-Ebmer. 2016. "Is education always reducing fertility? Evidence from compulsory schooling reforms." The Economic Journal 126:1823-1855.

Heckman, James J. and Joseph V. Hotz. 1986. The Sources of Inequality for Males in Panama's Labor Market. Journal of Human Resources 21: 507-42.

Hillmert, Steffen. 2013. Analysing Intergenerational Transmissions: From Social Mobility to Social Reproduction. Comparative Social Research. 30: 131-57. 
Hodge, R.W. 1966. Occupational mobility as a probability process. Demography 3: 1934.

Jaeger, Mads Meier. 2012. The Extended Family and Children's Educational Success. American Sociological Review 77: 903-22.

Lawrence, Matthew and Richard Breen. 2016. And Their Children After Them? The Effect of College on Educational Reproduction. American Journal of Sociology, 122: 53272.

Maralani, Vida. 2013. The Demography of Social Mobility: Black-White Differences in the Process of Educational Reproduction. American Journal of Sociology 118: 1509-58.

Mare, Robert D. 2011. A Multigenerational View of Inequality. Demography 48: 1-23.

Mare, Robert D. and Vida Maralani. 2006. The Intergenerational Effects of Changes in Women's Educational Attainments. American Sociological Review 71: 542-64.

Matras, Judah. 1961. Differential Fertility, Intergenerational Occupational Mobility, and Change in the Occupational Distribution: Some Elementary Relationships. Population Studies 15: 187-97.

Ní Bhrolcháin, M., \& Beaujouan, É. 2012. Fertility postponement is largely due to rising educational enrolment. Population Studies, 66: 311-327.

Preston, Samuel H. 1974. Differential Fertility, Unwanted Fertility, and Racial Trends in Occupational Achievement. American Sociological Review 39: 492-506.

Preston, Samuel H. and Cameron Campbell 1993. Differential Fertility and the Distribution of Traits: The Case of IQ. American Journal of Sociology. 98: 997-1019. 
Rendall, M.S., L. Clarke, H. E. Peters, N. Ranjit, and G. Verropoulou. 1999. Incomplete Reporting of Male Fertility in the United States and Britain: A Research Note. Demography 36: 135-144.

Robins, James M., Miguel A. Hernán and Babette Brumback. 2000. "Marginal Structural Models and Causal Inference in Epidemiology". Epidemiology 11: 550-60.

Song, Xi and Robert D.Mare 2015. Prospective Versus Retrospective Approaches to the Study of Intergenerational Mobility. Sociological Methods and Research 44: 555-84.

Schultz, T. Paul. 1993. Returns to Women's Education. In: Women's education in developing countries: Barriers, benefits, and policies. (Elizabeth M. King and M. Anne Hill, editors). Johns Hopkins University Press, pages 51-99.

VanderWeele, Tyler J. and Onyebuchi A. Arah. 2011. Bias Formulas for Sensitivity Analysis of Unmeasured Confounding for General Outcomes, Treatments, and Confounders. Epidemiology, 22: 42-52. 


\section{Tables}

Table 1: Descriptive Statistics

\begin{tabular}{|l|l|l|l|l|l|l|l|l|}
\hline & & & \multicolumn{4}{l}{ Married } & \multicolumn{3}{l|}{ Child } & Child with degree $^{1}$ \\
\hline & & & Yes & No & Yes & No & Yes & No \\
\hline Men & & & & & & & & \\
\hline No Degree & $\mathrm{N}$ & 3025 & 2753 & 272 & 2230 & 795 & 197 & 335 \\
\hline & $\%$ & 86.4 & 91.0 & 9.0 & 73.7 & 26.3 & 37.0 & 63.0 \\
\hline Degree & $\mathrm{N}$ & 477 & 417 & 60 & 340 & 137 & 69 & 23 \\
\hline & $\%$ & 13.6 & 87.4 & 12.6 & 71.3 & 28.7 & 75.0 & 25.0 \\
\hline & & & & & & & & \\
\hline Women & & & & & & & & \\
\hline No Degree & $\mathrm{N}$ & 3517 & 3335 & 182 & 2902 & 612 & 248 & 458 \\
\hline & $\%$ & 89.6 & 94.8 & 5.2 & 82.5 & 17.5 & 35.1 & 64.9 \\
\hline Degree & $\mathrm{N}$ & 410 & 358 & 52 & 305 & 105 & 73 & 41 \\
\hline & $\%$ & 10.4 & 87.3 & 12.7 & 74.4 & 25.6 & 64.0 & 36.0 \\
\hline
\end{tabular}

${ }^{1}$ At least one child with a degree among those having at least one child aged 23 or older.

Table 2: Comparison of Impacts of Key Variables on Probabilities of Parenthood and of Child aged 23 or older obtaining a University Degree, BHPS, Women

Propensity score weighted model estimation*

\begin{tabular}{|c|c|c|c|}
\hline $\begin{array}{c}\text { Outcome } \rightarrow \\
\text { Explanatory } \\
\text { Variable: }\end{array}$ & $\begin{array}{c}\text { Being a } \\
\text { parent }\end{array}$ & $\begin{array}{c}\text { Being a parent } \\
\text { and } \\
\text { Child degree }\end{array}$ & $\begin{array}{c}\text { Child degree } \\
\text { among Parents }^{\mathrm{b}}\end{array}$ \\
\hline $\begin{array}{c}\text { Having a } \\
\text { university }\end{array}$ & $\begin{array}{c}-0.100 \\
\text { degree }\end{array}$ & $\begin{array}{c}0.069 \\
(0.030)\end{array}$ & $\begin{array}{c}0.275 \\
(0.101)\end{array}$ \\
\hline $\mathrm{N}$ & 3927 & 3646 & 3646 \\
Selected N & & 1430 & 820 \\
\hline
\end{tabular}

\begin{tabular}{|c|c|c|c|}
\hline $\begin{array}{c}\text { Outcome } \rightarrow \\
\text { Explanatory } \\
\text { Variable: }\end{array}$ & $\begin{array}{l}\text { Being a } \\
\text { parent }\end{array}$ & $\begin{array}{c}\text { Being a parent } \\
\text { and } \\
\text { Child degree }\end{array}$ & $\begin{array}{c}\text { Child degree } \\
\text { among Parents }\end{array}$ \\
\hline $\begin{array}{c}\text { Having a } \\
\text { university } \\
\text { degree }\end{array}$ & $\begin{array}{l}-0.089 \\
(0.020)\end{array}$ & $\begin{array}{c}0.120 \\
(0.031)\end{array}$ & $\begin{array}{c}0.277 \\
(0.048)\end{array}$ \\
\hline
\end{tabular}

* Controls for a respondent's birth year (in 3-year cohorts) and whether foreign born; standard errors in parentheses. All structural equations weighted for selection into education category.

a Weighted for selection into education category and for selection into sample of either childless or parents for whom we observe the education of a child aged 23 or older.

b Weighted for selection into education category and for selection into sample of parents for whom we observe the education of a child aged 23 or older. 
Table 3: Comparison of Impacts of Key Variables on Probabilities of Parenthood and of Child aged 23 or older obtaining a University Degree, BHPS, Men

Propensity score weighted model estimation*

\begin{tabular}{|c|c|c|c|}
\hline $\begin{array}{c}\text { Outcome } \rightarrow \\
\text { Explanatory } \\
\text { Variable: }\end{array}$ & $\begin{array}{l}\text { Being a } \\
\text { parent }\end{array}$ & $\begin{array}{c}\text { Being a parent } \\
\text { and } \\
\text { Child degree }^{\mathrm{a}}\end{array}$ & $\begin{array}{c}\text { Child degree } \\
\text { among Parents }^{\mathrm{b}}\end{array}$ \\
\hline $\begin{array}{l}\text { Having a } \\
\text { university } \\
\text { degree }\end{array}$ & $\begin{array}{l}-0.040 \\
(0.027)\end{array}$ & $\begin{array}{c}0.097 \\
(0.035)\end{array}$ & $\begin{array}{c}0.386 \\
(0.067)\end{array}$ \\
\hline $\begin{array}{c}\mathrm{N} \\
\text { Selected } \mathrm{N}\end{array}$ & 3502 & $\begin{array}{l}3263 \\
1445\end{array}$ & $\begin{array}{c}3263 \\
624\end{array}$ \\
\hline
\end{tabular}

\begin{tabular}{|c|c|c|c|}
\hline $\begin{array}{c}\text { OLS } \\
\begin{array}{c}\text { Explanatory } \\
\text { Variable: }\end{array}\end{array}$ & $\begin{array}{c}\text { Being a } \\
\text { parent }\end{array}$ & $\begin{array}{c}\text { Being a parent } \\
\text { and } \\
\text { Child degree }\end{array}$ & $\begin{array}{c}\text { Child degree } \\
\text { among Parents }\end{array}$ \\
\hline $\begin{array}{c}\text { Having a } \\
\text { university } \\
\text { degree }\end{array}$ & -0.021 & 0.147 & 0.375 \\
$(0.022)$ & $(0.028)$ & $(0.055)$ \\
\hline
\end{tabular}

* Controls for a respondent's birth year (in 3-year cohorts) and whether foreign born; standard errors in parentheses. All structural equations weighted for selection into education category

a Weighted for selection into education category and for selection into sample of either childless or parents for whom we observe the education of a child aged 23 or older.

b Weighted for selection into education category and for selection into sample of parents for whom we observe the education of a child aged 23 or older. 
Table 4: Summary probabilities (from Figures 5 and 6) of the relationship between degree status of partners, fertility, and the probability of having a child who acquires a degree, according to sex of person

\begin{tabular}{|c|c|c|c|c|c|}
\hline & & \multicolumn{2}{|c|}{$\operatorname{pr}$ (Child) } & \multicolumn{2}{|c|}{ pr(Child has degree)* } \\
\hline & & $(1)$ & $(2)$ & (3) & (4) \\
\hline \multicolumn{2}{|c|}{ Degree status } & \multicolumn{4}{|c|}{ Sex of person } \\
\hline Man & Women & Male & Female & Male & Female \\
\hline Degree & Degree & .763 & .800 & .787 & .738 \\
\hline Degree & No Degree & .835 & .854 & .684 & .664 \\
\hline No Degree & Degree & .777 & .810 & .570 & .607 \\
\hline No Degree & No Degree & .828 & .861 & .351 & .338 \\
\hline
\end{tabular}

* among parents 


\section{Figures}

Figure 1: Percentage of people with degree (y-axis) by parental educational status and parental birth cohort ( $\mathrm{x}$-axis)
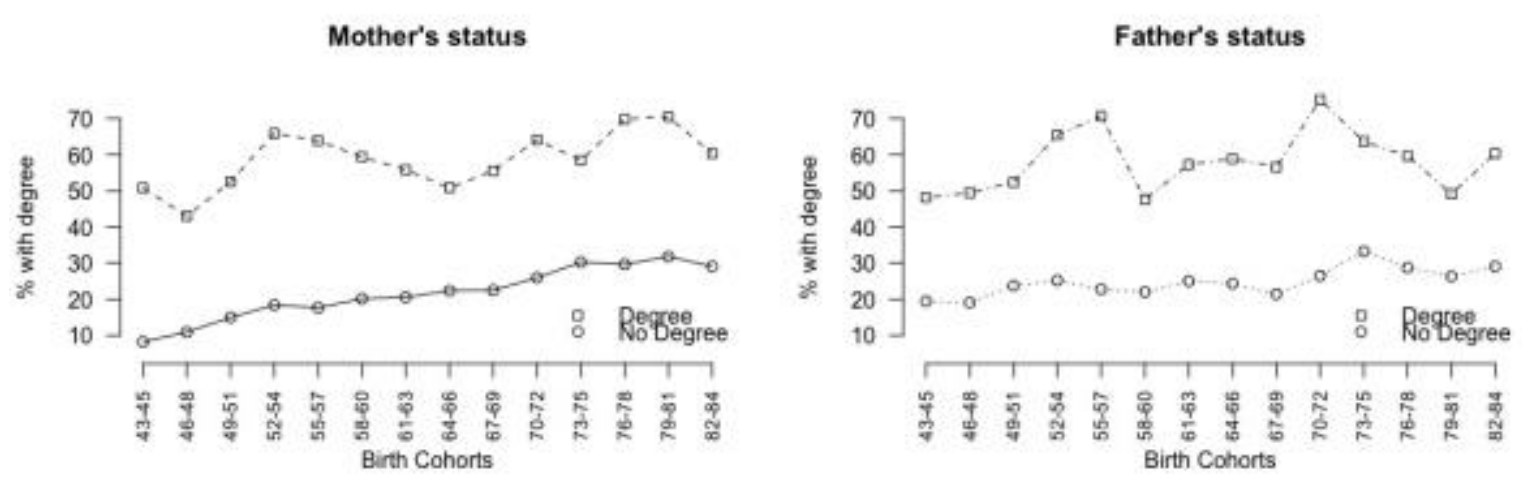
Figure 2: Percentage with child by degree status and birth cohort
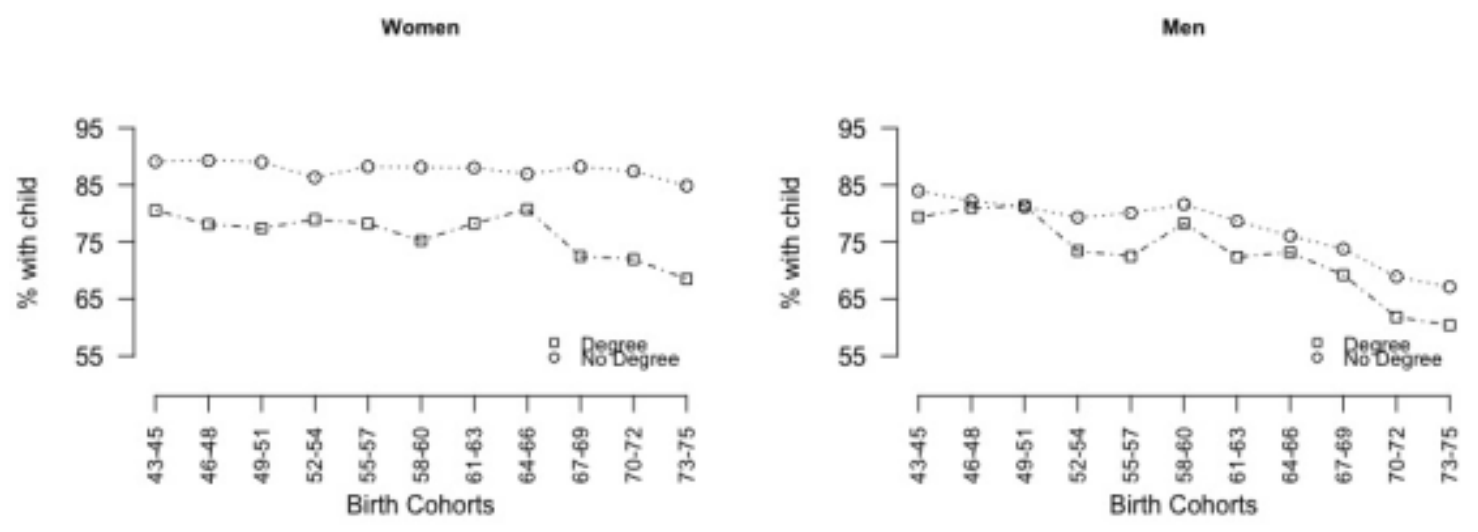
Figure 3: IPTW estimates of effect of degree on having child by birth cohort ( $95 \%$ confidence intervals also shown)

Women

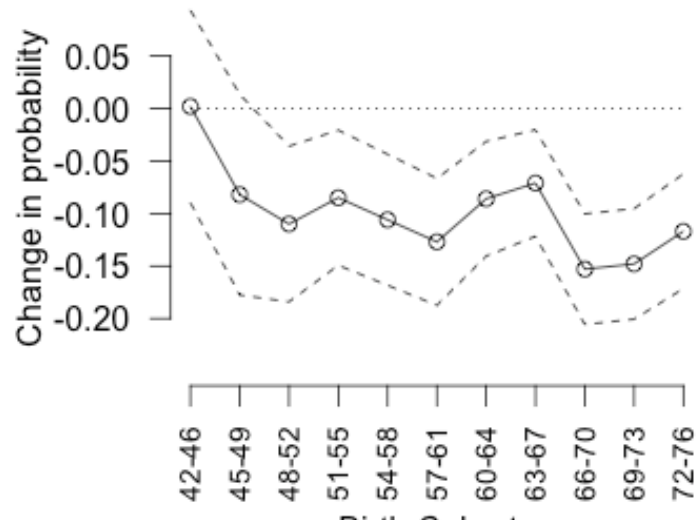

Birth Cohorts
Men

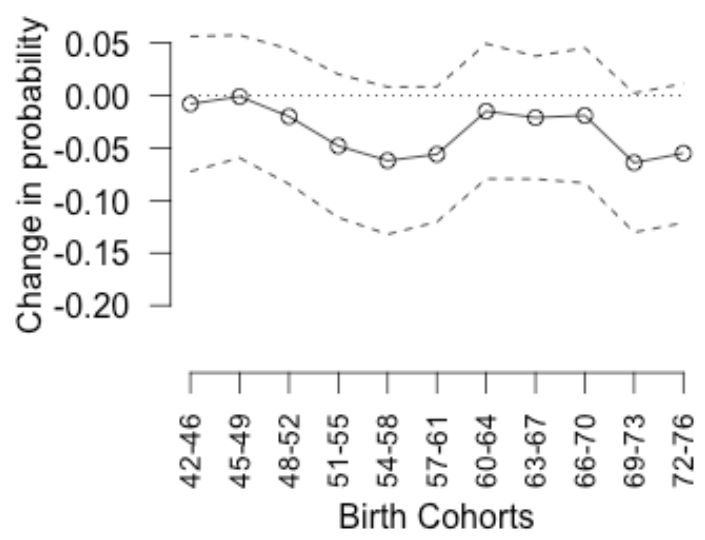


Figure 4: Model predictions: Conditional probabilities at each stage: Women born 193661 in Great Britain
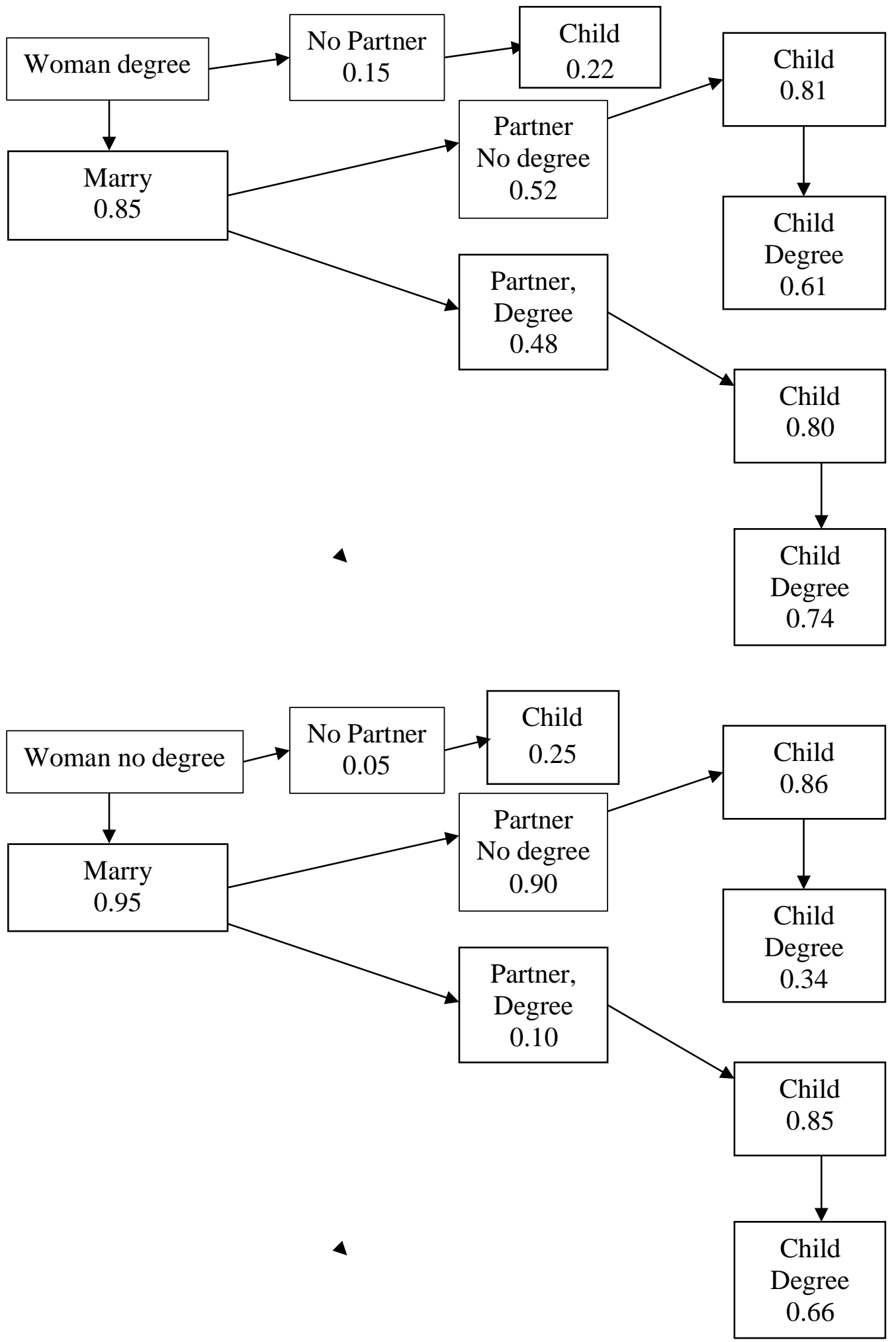
Figure 5: Model predictions: Conditional probabilities at each stage: Men born 1936-61 in Great Britain
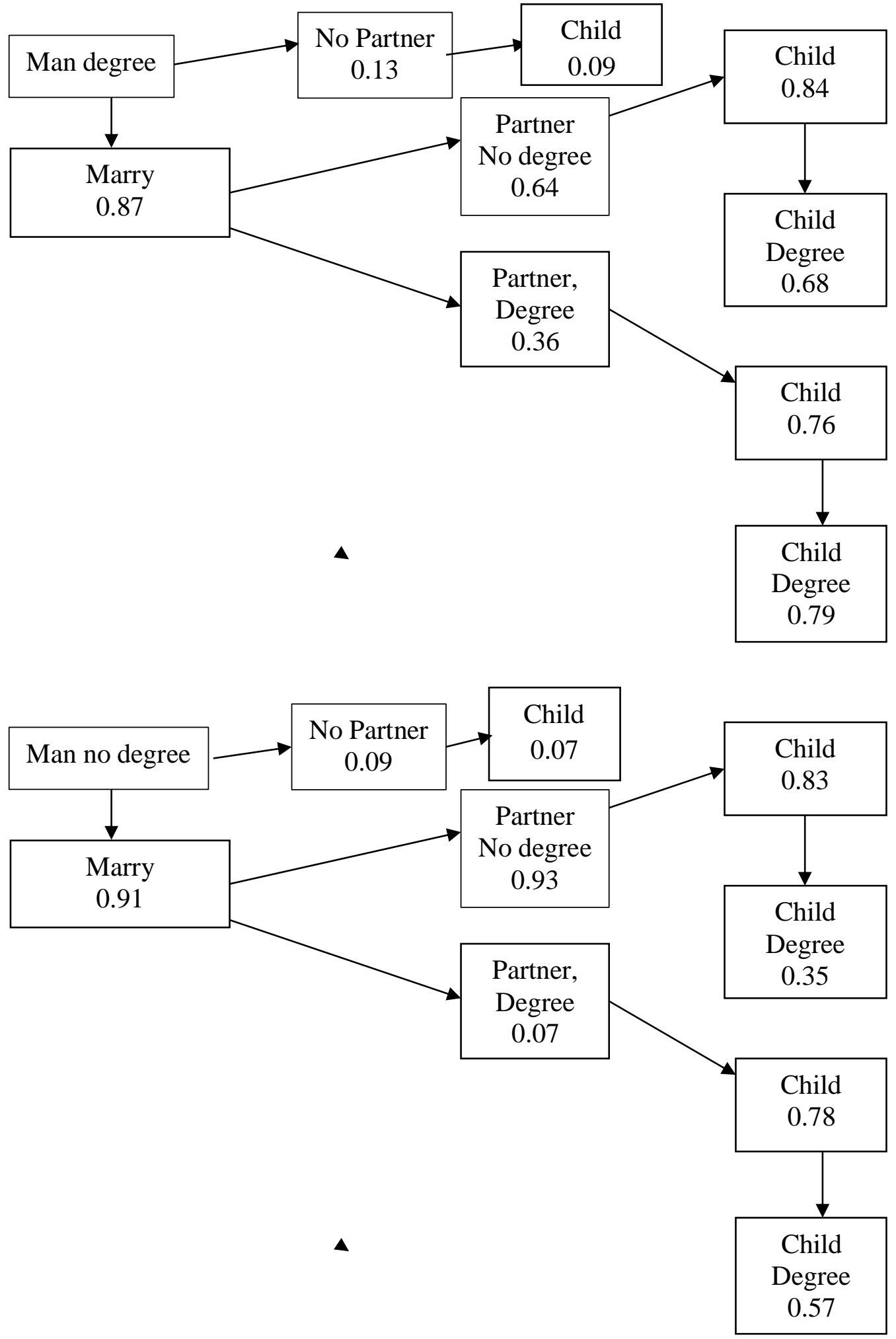


\section{Online Appendixes}

APPENDIX A: Construction of the BHPS dataset

The data set for our analysis was constructed in the following way from the BHPS file:

1. Obtain information about parents' occupations, social class etc. at respondent's age 14, date of birth, place of birth and other time-constant data from XWAVEDAT file.

2. Obtain information about parents' education from wave 13 of BHPS and combine with \#1).

3. Compute respondent's maximum level of education obtained over the entire 18 waves of the BHPS and mean level of equivalent household income over years in BHPS and merge into data.

4. Use information about partnership formation and childbearing from the British Household Panel Survey Consolidated Marital, Cohabitation and Fertility Histories file originally compiled by Chiara Pronzato and available from the UK Data Service. UK Data Archive Study Number 5629 User Guide (2010).

5. Match information about children of respondent who ever appeared as an adult in the BHPS using information on BHPS respondents' mother and father id's. From these data we obtain each matched child's maximum level of education over their years in BHPS and the first five waves of Understanding Society. 
APPENDIX B: Estimating models using IPTW

The estimate of ATE in equation [3] uses non-normalised weights. However, weighted regression routines (as in Stata or R) automatically normalise user-specified weights. Thus if we estimate the ATE using a weighted regression of $C$ on $D$, with weights specified as above, the program will return an estimate equal to

$$
A T E_{n}=\frac{1}{N_{1}} \quad{ }_{1}^{N_{1}}\left(C_{i} D_{i} w_{i 1}\right) \quad \frac{1}{N_{0}} \quad{ }_{1}^{N_{0}}\left(C_{i}\left(1 \quad D_{i}\right) w_{i 0}\right)
$$

where the first sum is over the $N_{1}$ treated observations and the second is over the $N_{0}$ untreated cases. In this case the weights for the treated and untreated are (Cerulli 2014):

$$
\begin{aligned}
& w_{i 1}=\frac{1 / p\left(X_{i}\right)}{\frac{1}{N_{1}}{ }_{1}^{N_{1}} D_{i} / p\left(X_{i}\right)} \\
& w_{i 0}=\frac{1 /\left[\begin{array}{ll}
1 & p\left(X_{i}\right)
\end{array}\right]}{\frac{1}{N_{0}}{ }_{1}^{N_{0}}\left(\begin{array}{ll}
1 & \left.D_{i}\right) /\left[\begin{array}{ll}
1 & p\left(X_{i}\right)
\end{array}\right]
\end{array}\right.}
\end{aligned}
$$

The normalised ATE estimator in [B1] is the difference between the weighted mean outcome in the treatment group and the weighted mean outcome in the non-treatment group. This is a 'natural estimator' of the ATE, analogous to OLS. Indeed, if the mean probability of treatment is constant across observations, the expression in [B1] reduces to the OLS estimate of ATE (i.e. pure difference in means between the two groups).

Using our female sample, the estimated ATE using non-normalised weights is -0.125 (s.e. $=0.031$ ), while the estimated ATE using normalised weights is -0.096 (s.e. $=0.031)$. A comparison with the OLS estimate of -0.081 (s.e. $=0.020$ ) indicates that women with a degree have values of $X_{i}$ that make them more likely to have a child. ${ }^{9}$ In the propensity

\footnotetext{
${ }^{9}$ The estimates reported in this section differ from those reported in Tables 2 and 3 (and on which we base our conclusions) because later we control for birth cohort and whether or not someone was foreign born. Here we do not because this allows us to make a direct comparison between the descriptive figures shown in Table 1 and the iptw estimates. The calculation of the standard errors in the non-normalized estimate takes account of the fact that $p\left(X_{i}\right)$ is estimated rather than known (using the treatrew.ado
} 
score weighting approach, people with a low (high) probability of treatment receive a higher (lower) weight in the estimation. This may be problematic when there are people who have a very low or very high probability of treatment. Thus, we might confine the estimation to those who have a probability of treatment between some limits. For example, if we confine the estimation to women who have an estimated probability of treatment above 0.01 the non-normalised and normalised ATE estimators are -0.122 and -0.098 , respectively, and if the threshold is raised to 0.025 , they are 0.106 and -0.097 , respectively. ${ }^{10}$ At least in this example, the ATE estimates -- and especially the normalized ATE estimates -- do not appear very sensitive to the exclusion of the bottom of the treatment probability distribution. ${ }^{11}$

routine of Cerulli (2014)). The uncertainty of the predicted $p\left(X_{i}\right)$ is not taken into account in the calculation of the standard error of the normalized ATE estimate from the weighted linear regression, but the similar standard error to the non-normalised weighted estimate suggests the bias in the standard error estimate is small.

${ }^{10}$ Because of this pre-screening, the standard errors of these estimates would need adjustment to reflect the sampling variance in the predicted probability of treatment.

${ }^{11}$ Robins et al. (2000) suggest using 'stabilised weights' which multiply $1 / \mathrm{p}\left(\mathrm{X}_{\mathrm{i}}\right)$ by the sample analogue of $E\left[D_{i}\right]$ and $1 /\left[1-p\left(X_{i}\right)\right]$ by the sample analogue of $1-E\left[D_{i}\right]$. This adjustment does not affect the estimate of ATE using normalised weights or its standard error, but it strongly affects the ATE estimate with nonnormalised weights. 


\section{Appendix C Propensity Scores}

Table C1: Propensity Score Estimates E $\left[D_{i} \mid X_{i}\right]$, Women

Logistic regression

Log likelihood $=-1125.4095$
Number of obs=

LR chi2 (24)

Prob > chi2

Pseudo R2
3927

377.57

0.0000

0.1437

\begin{tabular}{|c|c|c|c|c|c|c|}
\hline madeg & Coef. & Std. Err. & z & $\mathrm{P}>|\mathrm{z}|$ & [95\% Conf. & Interval] \\
\hline \multicolumn{7}{|l|}{ gpasclass } \\
\hline 2 & -.0536196 & .2296836 & -0.23 & 0.815 & -.5037912 & .3965521 \\
\hline 3 & -.7762744 & .2817271 & -2.76 & 0.006 & -1.328449 & -.2240995 \\
\hline 4 & -1.073088 & .2405364 & -4.46 & 0.000 & -1.544531 & -.6016454 \\
\hline 5 & -1.479679 & .2966017 & -4.99 & 0.000 & -2.061008 & -.8983507 \\
\hline 6 & -2.059708 & .4450537 & -4.63 & 0.000 & -2.931997 & -1.187419 \\
\hline 7 & -.302885 & .424452 & -0.71 & 0.475 & -1.134796 & .5290255 \\
\hline \multicolumn{7}{|l|}{ grandpa2 } \\
\hline 3 & .5261455 & .2020789 & 2.60 & 0.009 & .1300782 & .9222128 \\
\hline 4 & .3916504 & .1692026 & 2.31 & 0.021 & .0600195 & .7232814 \\
\hline 5 & .8147004 & .2934065 & 2.78 & 0.005 & .2396342 & 1.389767 \\
\hline 9 & -.3058389 & .3324023 & -0.92 & 0.358 & -.9573353 & .3456576 \\
\hline \multicolumn{7}{|l|}{ grandma2 } \\
\hline 3 & .3351291 & .1801417 & 1.86 & 0.063 & -.0179422 & .6882003 \\
\hline 4 & .5314802 & .1888155 & 2.81 & 0.005 & .1614086 & .9015517 \\
\hline 5 & 1.267611 & .3643096 & 3.48 & 0.001 & .5535773 & 1.981645 \\
\hline 9 & -.022903 & .3252111 & -0.07 & 0.944 & -.660305 & .6144989 \\
\hline gmaocc & .1945001 & .1158012 & 1.68 & 0.093 & -.0324661 & .4214663 \\
\hline \multicolumn{7}{|l|}{ mabthcoh } \\
\hline 39 & -.0974355 & .3955934 & -0.25 & 0.805 & -.8727844 & .6779133 \\
\hline 42 & .3095671 & .3468181 & 0.89 & 0.372 & -.3701839 & .9893182 \\
\hline 45 & .4667443 & .3275062 & 1.43 & 0.154 & -.175156 & 1.108645 \\
\hline 48 & .7163991 & .3211148 & 2.23 & 0.026 & .0870256 & 1.345773 \\
\hline 51 & .8346477 & .3160127 & 2.64 & 0.008 & .2152743 & 1.454021 \\
\hline 54 & 1.200313 & .3115317 & 3.85 & 0.000 & .5897225 & 1.810904 \\
\hline 57 & 1.046406 & .3107933 & 3.37 & 0.001 & .4372619 & 1.655549 \\
\hline 60 & 1.009688 & .3206582 & 3.15 & 0.002 & .3812097 & 1.638167 \\
\hline foreignb & .5238292 & .1919679 & 2.73 & 0.006 & .1475791 & .9000793 \\
\hline _cons & -2.447457 & .3664683 & -6.68 & 0.000 & -3.165721 & -1.729192 \\
\hline
\end{tabular}

Note:

gpasoclass is father's social class (highest is 6,7=unknown) grandpa2 is father's education (highest is 5, 9=unknown) grandma2 is mother's education (highest is 5, 9=unknown) gmaocc is mother had a job when aged $14(0,1)$ mabthcoh is 3-year birth cohort: $36-38$, 39-41, etc. foreignb is foreign born $((0,1)$ 
Table C2: Propensity score estimates E[ $\left[S_{i 1} \mid Z_{i}, X_{i}\right]$, Women

\begin{tabular}{|c|c|c|c|}
\hline \multirow[t]{3}{*}{ Logistic regression } & Number of obs & $=$ & 3646 \\
\hline & LR chi2(27) & $=$ & 444.97 \\
\hline & Prob > chi2 & $=$ & 0.0000 \\
\hline Log likelihood $=-2219.3361$ & Pseudo R2 & $=$ & 0.0911 \\
\hline
\end{tabular}

\begin{tabular}{|c|c|c|c|c|c|c|}
\hline select & Coef. & Std. Err. & z & $\mathrm{P}>|z|$ & [95\% Conf. & Interval] \\
\hline \multicolumn{7}{|l|}{ mabthcoh } \\
\hline 39 & .0449653 & .2035755 & 0.22 & 0.825 & -.3540355 & .443966 \\
\hline 42 & .3460674 & .1874866 & 1.85 & 0.065 & -.0213995 & .7135343 \\
\hline 45 & .6815211 & .1792996 & 3.80 & 0.000 & .3301003 & 1.032942 \\
\hline 48 & 1.048134 & .1772714 & 5.91 & 0.000 & .7006883 & 1.395579 \\
\hline 51 & 1.320089 & .1781484 & 7.41 & 0.000 & .9709241 & 1.669253 \\
\hline 54 & 1.554649 & .1802804 & 8.62 & 0.000 & 1.201305 & 1.907992 \\
\hline 57 & 1.30627 & .1783423 & 7.32 & 0.000 & .9567254 & 1.655814 \\
\hline 60 & 1.005832 & .1868827 & 5.38 & 0.000 & .6395487 & 1.372115 \\
\hline foreignb & .2539536 & .1510953 & 1.68 & 0.093 & -.0421877 & .5500949 \\
\hline \multicolumn{7}{|l|}{ gpasclass } \\
\hline 2 & .0858869 & .2067078 & 0.42 & 0.678 & -.3192529 & .4910267 \\
\hline 3 & .0850313 & .2290302 & 0.37 & 0.710 & -.3638597 & .5339223 \\
\hline 4 & -.0829474 & .2047895 & -0.41 & 0.685 & -.4843275 & .3184327 \\
\hline 5 & -.0544811 & .2180587 & -0.25 & 0.803 & -.4818684 & .3729062 \\
\hline 6 & -.1289899 & .2443328 & -0.53 & 0.598 & -.6078734 & .3498936 \\
\hline 7 & .1288843 & .3586873 & 0.36 & 0.719 & -.57413 & .8318985 \\
\hline \multicolumn{7}{|l|}{ grandpa2 } \\
\hline 3 & .0478504 & .1541167 & 0.31 & 0.756 & -.2542129 & .3499136 \\
\hline 4 & -.1122201 & .11694 & -0.96 & 0.337 & -.3414182 & .1169781 \\
\hline 5 & .0818209 & .2650908 & 0.31 & 0.758 & -.4377475 & .6013892 \\
\hline 9 & -.0207052 & .1890333 & -0.11 & 0.913 & -.3912037 & .3497933 \\
\hline \multicolumn{7}{|l|}{ grandma2 } \\
\hline 3 & .2627255 & .1350357 & 1.95 & 0.052 & -.0019395 & .5273906 \\
\hline 4 & .4378436 & .1484186 & 2.95 & 0.003 & .1469484 & .7287388 \\
\hline 5 & .4754785 & .3494091 & 1.36 & 0.174 & -.2093507 & 1.160308 \\
\hline 9 & -.2948876 & .1874994 & -1.57 & 0.116 & -.6623797 & .0726045 \\
\hline gmaocc & -.0335041 & .080889 & -0.41 & 0.679 & -.1920437 & .1250355 \\
\hline \multicolumn{7}{|l|}{ memorig } \\
\hline 5 & -.7763112 & .1155048 & -6.72 & 0.000 & -1.002696 & -.5499261 \\
\hline 6 & -1.061572 & .120437 & -8.81 & 0.000 & -1.297624 & -.8255201 \\
\hline 7 & -1.118187 & .1129244 & -9.90 & 0.000 & -1.339514 & -.8968589 \\
\hline _cons & -.8617479 & .2542268 & -3.39 & 0.001 & -1.360023 & -.3634725 \\
\hline
\end{tabular}

memorig is sample origin: original sample(reference); $5=$ Wales new sample; $6=$ Scotland new sample; $7=$ Northern Ireland new sample. 
Figure C1: Distribution of Propensity Score for Degree, Women

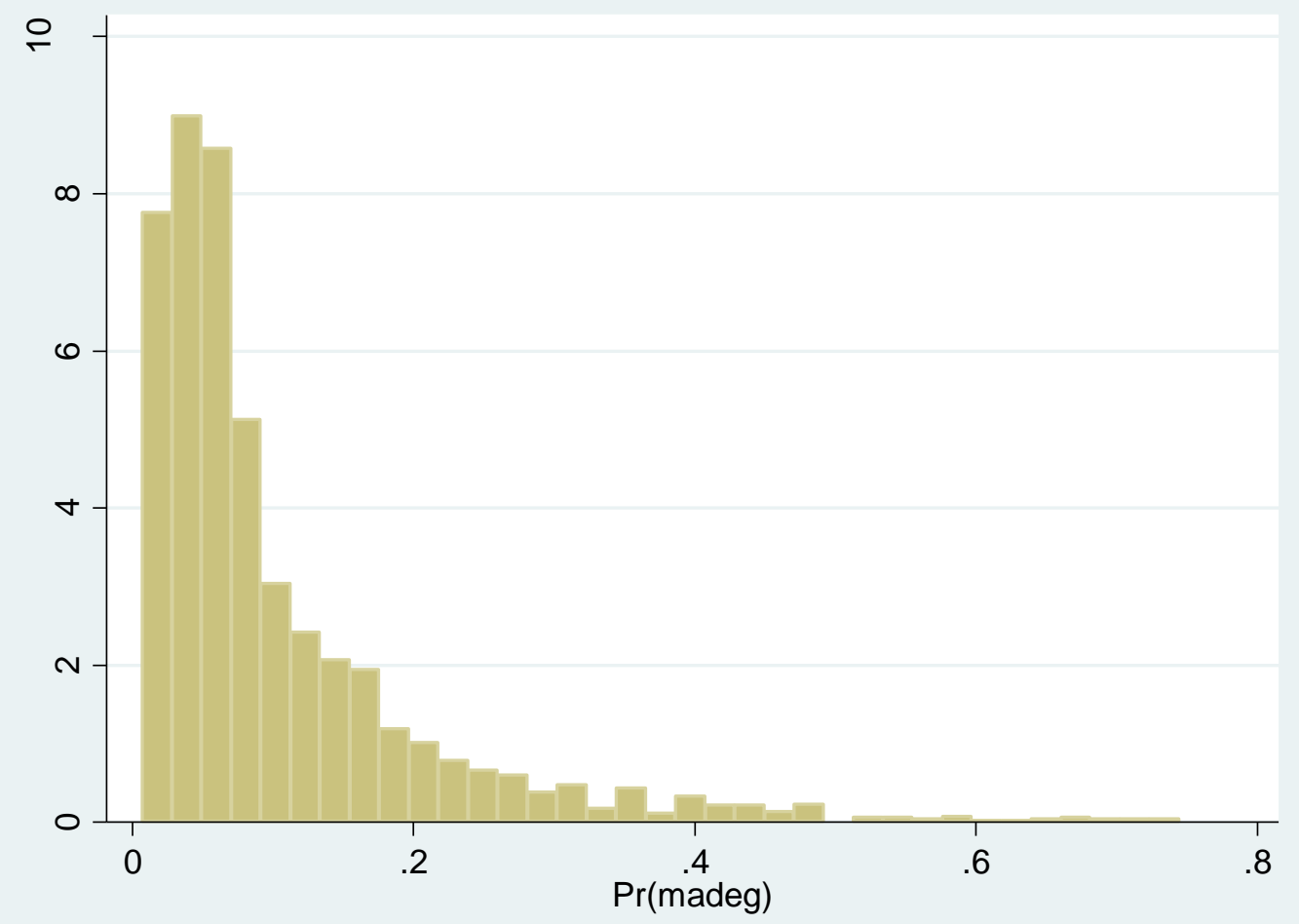




\section{APPENDIX D: Sensitivity Analysis}

Let $U$ be an unmeasured 'confounder' and let $P[U / D, X]$ be the probability distribution of $U$ given treatment $D$ (parent degree or not) and covariates $X$.

Assume that $E[Y \mid D, X, U]-E\left[Y \mid D, X, U^{\prime}\right]$ does not vary with $D$, where $U^{\prime}$ is some chosen reference value for the unmeasured confounder $U$, and $X$ are the covariates used in the causal estimates. Also assume that $P[U \mid D=1, X]-P[U \mid D=0, X]$ does not vary between the strata of $X$. Then VanderWeele and Arah (2011, Theorem 1) show that the bias from an estimator adjusting for $X$ but not for $U$ is given by:

Bias $=\sum_{\mathrm{u}}\left\{\mathrm{E}[\mathrm{Y} \mid \mathrm{D}, \mathrm{X}, \mathrm{U}]-\mathrm{E}\left[\mathrm{Y} \mid \mathrm{D}, \mathrm{X}, \mathrm{U}^{\prime}\right]\right\}\{\mathrm{P}[\mathrm{U} \mid \mathrm{D}=1, \mathrm{X}]-\mathrm{P}[\mathrm{U} \mid \mathrm{D}=0, \mathrm{X}]\}$

(the summation over $\mathrm{u}$ is replaced by an appropriate integral if $\mathrm{U}$ is a continuous variable).

If $\mathrm{E}[\mathrm{Y} \mid \mathrm{D}, \mathrm{X}, \mathrm{U}]-\mathrm{E}\left[\mathrm{Y} \mid \mathrm{D}, \mathrm{X}, \mathrm{U}^{\prime}\right]=\gamma\left(\mathrm{u}-\mathrm{u}^{\prime}\right)$ is a constant over $\mathrm{X}$, then

Bias $=\sum_{\mathrm{u}} \gamma\left(\mathrm{u}-\mathrm{u}^{\prime}\right)\{\mathrm{P}[\mathrm{U} \mid \mathrm{D}=1, \mathrm{X}]-\mathrm{P}[\mathrm{U} \mid \mathrm{D}=0, \mathrm{X}]\}=\gamma\{\mathrm{E}[\mathrm{U} \mid \mathrm{D}=1]-\mathrm{E}[\mathrm{U} \mid \mathrm{D}=0)\}=\gamma \delta$

where $\delta=\mathrm{E}[\mathrm{U} \mid \mathrm{D}=1]-\mathrm{E}[\mathrm{U} \mid \mathrm{D}=0)]$

If $U$ is binary, then $\delta=\mathrm{P}[\mathrm{U}=1 \mid \mathrm{D}=1]-\mathrm{P}[\mathrm{U}=0 \mid \mathrm{D}=0]$ and $\gamma=\mathrm{E}[\mathrm{Y} \mid \mathrm{U}=1]-\mathrm{E}[\mathrm{Y} \mid \mathrm{U}=$ $0]$.

We use the propensity score to benchmark the possible bias in the causal estimate. This is best understood using an example. Table D1 shows the sensitivity of our estimate of the effect of having a University degree on having one or more children. We estimated this as -0.100 ( $\mathrm{se}=.03$ ). In the table we show how our estimate changes with different values of $\gamma$ and $\delta$. These values range from -3 to 3. $\gamma$ is calibrated using the regression coefficient of the propensity score on being a parent: this is 0.111 . So a unit change in $\gamma$ (from -3 to 3 ) is equal to a change of 0.111 or, in other words, the effect of the observed 
propensity score on the outcome. $\delta$ is calibrated using the coefficient from the regression of the propensity score on the treatment, $\mathrm{D}$, which is 0.121 . In our sensitivity analyses, then, we are asking: how would the causal estimate be affected if $U$ affected the outcome by some multiple of the impact of the propensity score on the outcome and if the difference in $U$ between degree and non-degree persons was some multiple of the average differences in propensity scores? Given the standard error of our estimate of .03 , any value shown in Table D1 that has an absolute value of less than .059 is not significant at $\mathrm{p}<.05$. This occurs only when both $\gamma$ and $\delta$ are at least twice as large (in absolute terms) as we observe for the propensity score.

Table D2 shows the same analysis for the outcome of having a child with a degree among parents. Our estimate for women is 0.275 (se = .101). The value used to calibrate $\delta$ is unchanged but in this case we use a value of 0.619 for $\gamma$. In this case, an entry in the table with an absolute value of less than .2 is not statistically significant at $p$ $<.05$. This occurs only if both $\gamma$ and $\delta$ are at least as large (in absolute terms) as we observe for the propensity score.

Clearly, the causal estimate for the effect of a degree on having a child is more robust than that for having a child with a degree, conditioning on parenthood. But it is the former than drives our finding of a large difference between the conditional and unconditional estimates of educational reproduction. 
Table D1: Causal Effect of Degree on having at least 1 child (women)

\begin{tabular}{|l|l|l|l|l|l|l|l|}
\hline & Delta & \multicolumn{7}{l|}{} \\
\hline Gamma & -3 & -2 & -1 & 0 & 1 & 2 & 3 \\
\hline-3 & -0.220 & -0.180 & -0.140 & -0.100 & -0.060 & -0.020 & 0.020 \\
\hline-2 & -0.180 & -0.153 & -0.127 & -0.100 & -0.073 & -0.047 & -0.020 \\
\hline-1 & -0.140 & -0.127 & -0.113 & -0.100 & -0.087 & -0.073 & -0.060 \\
\hline 0 & -0.100 & -0.100 & -0.100 & -0.100 & -0.100 & -0.100 & -0.100 \\
\hline 1 & -0.060 & -0.073 & -0.087 & -0.100 & -0.113 & -0.127 & -0.140 \\
\hline 2 & -0.020 & -0.047 & -0.073 & -0.100 & -0.127 & -0.153 & -0.180 \\
\hline 3 & 0.020 & -0.020 & -0.060 & -0.100 & -0.140 & -0.180 & -0.220 \\
\hline
\end{tabular}

Table D2: Causal Effect of Degree on child getting degree among parents (women)

\begin{tabular}{|l|l|l|l|l|l|l|l|}
\hline & \multicolumn{7}{|l}{ Delta } \\
\hline Gamma & -3 & -2 & -1 & 0 & 1 & 2 & 3 \\
\hline-3 & -0.399 & -0.174 & 0.050 & 0.275 & 0.500 & 0.724 & 0.949 \\
\hline-2 & -0.174 & -0.025 & 0.125 & 0.275 & 0.425 & 0.575 & 0.724 \\
\hline-1 & 0.050 & 0.125 & 0.200 & 0.275 & 0.350 & 0.425 & 0.500 \\
\hline 0 & 0.275 & 0.275 & 0.275 & 0.275 & 0.275 & 0.275 & 0.275 \\
\hline 1 & 0.500 & 0.425 & 0.350 & 0.275 & 0.200 & 0.125 & 0.050 \\
\hline 2 & 0.724 & 0.575 & 0.425 & 0.275 & 0.125 & -0.025 & -0.174 \\
\hline 3 & 0.949 & 0.724 & 0.500 & 0.275 & 0.050 & -0.174 & -0.399 \\
\hline
\end{tabular}


Appendix E: Calculation of full impact of having a degree

$D_{i}, D_{p i}$ and $Y_{i}$ are dichotomous indicators of degree status for a woman, her partner and her child, respectively. $P_{i}$ and $C_{i}$ are indicators of having a partner and having a child, respectively. $E$ is the expectation operator and $j=0,1$.

$$
\begin{aligned}
& E\left(Y_{i} \mid D_{i}=j\right)= \\
& E\left(P_{i} \mid D_{i}=j\right) \bullet\left\{E\left(D_{p i} \mid P_{i}=1, D_{i}=j\right) \bullet E\left(C_{i} \mid D_{i}=j, P_{i}=1, D_{p i}=1\right) \bullet E\left(Y_{i} \mid D_{i}=j, P_{i}=1, D_{p i}=1, C_{i}=1\right)\right. \\
& +\left[1-E\left(D_{p i} \mid P_{i}=1, D_{i}=j\right)\right] \bullet E\left(C_{i} \mid D_{i}=j, P_{i}=1, D_{p i}=0\right) \bullet E\left(Y_{i} \mid D_{i}=j, P_{i}=1, D_{p i}=0, C_{i}=1\right\} \\
& +\left[1-E\left(P_{i} \mid D_{i}=j\right)\right] \bullet E\left(C_{i} \mid D_{i}=j, P_{i}=0\right) \bullet E\left(Y_{i} \mid D_{i}=j, P_{i}=0, C_{i}=1\right) \\
& E\left(Y_{i} \mid D_{i}=1\right)-E\left(Y_{i} \mid D_{i}=0\right)=\text { overall-effect }
\end{aligned}
$$

Overall effect of degree $=0.16$ for women and 0.23 for men. 